\title{
Experimental studies on biodegradable and swelling characteristics of natural fibers composites
}

\author{
Bharath K.N. ${ }^{1}$, Swamy R.P. ${ }^{2}$, Mohan KumarG.C. ${ }^{3}$ \\ ${ }^{1}$ Dept. of Mechanical Engineering, G.M. Institute of Technology, Davangere, Karnataka, India \\ ${ }^{2}$ Dept. of Mechanical Engineering, Univ. B.D.T College of Engineering, Davangere, Karnataka \\ ${ }^{3}$ Dept of Mechanical Engineering, National Institute of Technology, Suratkal, Karnataka, India, kn.bharath@gmail.com
}

\begin{abstract}
Natural fibers are gaining the interest of scientists and engineers in packaging, low cost housing and other general applications. In the present study, biodegradable property and swelling properties of different volume fraction of randomly distributed areca fibre and maize powder reinforced urea formaldehyde composites has been investigated. Areca fibres were chemically treated with dilute $\mathrm{NaOH}$ solution; composites were prepared by hydraulic hot press at $1400 \mathrm{C}$ and $2 \mathrm{MPa}$ of pressure. Composites are cured under ambient conditions for 5 hours. The tests were conducted according to ASTM standards. The degradation involves bond scission reactions in the backbone of polymers, when the original form disappears. The composite absorbs some amount of moisture present in the compost in the early stages and there is an increase in the rate of the reaction between the enzymes secreted by the organism and the polymer chains or additives, which make up the compound. It is a very slow process since the areca fibers and maize powder do not decompose at a faster rate. It has been observed that at the initial stages the specimens shows increase in the weights for nearly one month and then starts loosing its weight showing the biodegradability. In swelling, it absorbs about $30-40 \%$ of its thickness. Compared to conventional woodbased particle board it is very small where water absorption for wood-based particle board is more than $40 \%$. Therefore this experiment shows that the composite made of areca fibers and maize powder have significantly less water absorption.
\end{abstract}

Keywords- Natural fibers, urea formaldehyde resin, hybrid composite, volume fraction

\section{Introduction}

Nowadays composites are gaining importance in all Engineering applications. Synthetic fibers are being used as structural or non-structural applications. They are being used because of their good physical, chemical and mechanical properties. However, they are limited in the domestic applications. In this context a natural fibre finds domestic applications as they are degradable, non-expensive and renewable. Natural fiber composites possess better electrical resistance, good thermal and acoustic insulating properties, good moisture resistance and high resistance to fracture. Natural fibers are ecofriendly and hence a lot of research is focused on their reinforced composites. Natural fibres are gaining the interest of scientist and engineers in packaging, low cost housing and other general applications. Commonly used natural fibres are banana fibres, cotton, coir, sisal jute. The husk of the areca is a hard fibrous portion covering the endosperm it constituting 30 to $45 \%$ of the total volume of the fruit. It is estimated that one lakh tonnes of the dry husk is available annually. Areca fibers are hard and show similarity in cellular structure. Less work has been carried out to evaluate the morphology and physical properties of areca fibers [1]. Maize stems are in continuous use in rural, as partitioning walls, wind shields and heat resistance layer. Even though this maize is not durable, it is still in use because of its availability at no cost. An appropriate methodology of chemical treatment and processing of maize stems, identification of suitable adhesives for gluing and other relevant topics are the urgent need in the development maize materials to develop a new material with the maize [2]. Many references have been reported on the use of wood / agro wastes as raw materials for the preparation of particleboards. Most plywood and particleboards are available in the market which is bonded with urea formaldehyde.

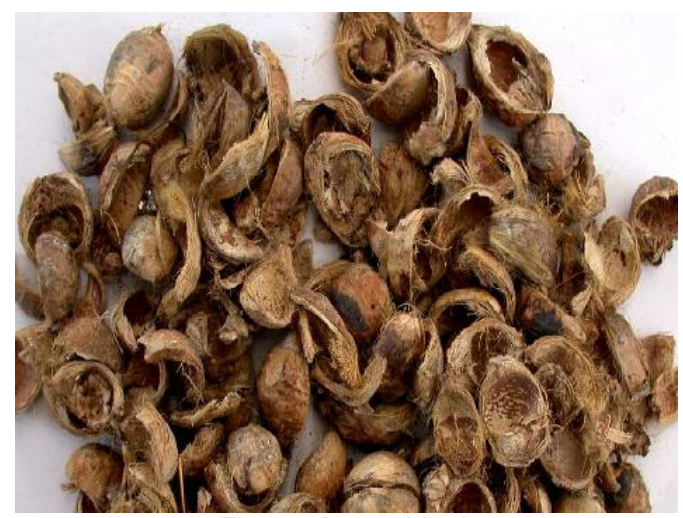

Fig. 1- Areca Husk

Fig..1 shows the areca husk from which areca fibres are been extracted. The total hemi cellulose content of the fibre was found to be $35 \%$ to $64.8 \%$. The areca fibre contains a higher percentage of hemi cellulose. Lignin content is comparatively low. Areca fibres contain $13 \%$ to $24.8 \%$ of lignin and negligible cellulose. The fibre was found to be $4.4 \%$ ash content. The idea of using areca husk fibre as a packaging and 
building material came into practice with the early use of areca husk because areca husk is slow degradable, available free of cost. The mechanical and moisture absorption properties of natural fibres reinforced composites have been reported by Verma [3] when alkali treated jute/epoxy composites are exposed to high temperature $100^{\circ} \mathrm{C}$ results in the decrease in adhesion of the fiber and matrix and increase in the susceptibility of the composite to moisture. Prasad [4] have studied the behavior of untreated and alkali treated fibres for coir-polyester composites and concluded that flexural strength, modulus and impact strength of composites containing alkali-treated fibers were higher than the same volume fractions of untreated fibers. Ghosh [5] studied modification of jute by phenolic resin in composites and it was found that there was an increase in adhesion between the matrix and fiber. Sridhar [6] have reported that lignin coating has been shown to bring down the resin consumption without affecting the properties of the fibers. They have also reported that ehylene diamine treatment on to jute fibers impart hydrophobicity and thereby reduce moisture absorption. Giridhar [7] have reported that sisal fibres absorbs less moisture than jute, since they are compact but their composites exhibits much higher absorption levels than jute. Mohan Kumar and Vrushabhendrappa have studied the behavior of natural maize fiber and coir fiber reinforced composites and concluded that composite prepared from the natural maize indicate the better results than alkali or acidic treated maize composites due to delamination within a short time [1].

The following are the details of Areca fiber specimen.

Status :Dried

Selection : Random

Number of Specimen : 100 Nos.

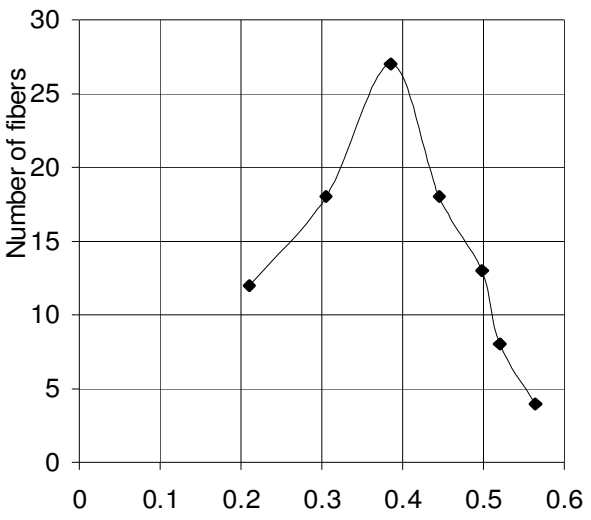

Average Fiber diameter, $\mathrm{mm}$

Fig. 2- Variation of fiber size of areca fiber Fig. 2 shows the variation of fiber size of areca fiber. The sizes of about 100 fibers were measured and distribution curve is plotted. The fibers diameter varies from 0.21 to $0.56 \mathrm{~mm}$ for randomly selected 100 fibers. From this distribution curve the mean diameter of the areca fibers is found to be $0.385 \mathrm{~mm}$. The calculated average diameter of the areca fibers is 0.39305 $\mathrm{mm}$. From this it can be conclude that the mean diameter and the calculated average diameter are the same and are equal to $0.39 \mathrm{~mm}$. Therefore the average diameter of the areca fibers varies from $0.39 \pm 0.12 \mathrm{~mm}$. In the present study, biodegradable property and swelling property for different volume UF resin of randomly distributed areca fiber and maize powder reinforced urea formaldehyde composites have been investigated.

\section{Methodology}

Areca Husk was soaked in water for about 8 day. The soaking process loosens the fibers and dried for 3 days. The fibers were extracted machining process. Maize powder was extracted by the pulversizer through machining process and this maize powder is taken to the blower which separates the fine maize powder from the unwanted dust particles. Finally fine maize powder was obtained which is taken for the next process. Known quantities of maize powder, ammonium chloride hardener and urea formaldehyde resin are mixed thoroughly. A mould made of aluminum sheet dimension of $320 \times 320 \mathrm{~mm}$ was used to prepare the board. In order to get required dimension of $320 \times 320 \times 12$ $\mathrm{mm} 3$ of board, two frames of same dimension were placed adjacently on the mould. Thoroughly mixed mixture of areca fibers, maize powder, $3 \%$ of hardener and urea formaldehyde resin was taken and placed in the mould uniformly. A layer of aluminum foil was placed both at the top and bottom of the board so that board can be easily taken out from the mould. A hot hydraulic press is used to prepare the boards. The working principle of this press is, the material from which board is to be prepared is compressed at an appropriate temperature and pressure. This set up is kept for the known duration of time. The mould is placed in hydraulic press, which is maintained at $150^{\circ} \mathrm{C}$, and then a pressure of 100 bars is applied. The set up is maintained undisturbed about an hour. After an hour, the mould is taken out and allowed to cool for halfan-hour and remove the composite board from the mould.

\section{Experimentation}

A Known quantities of maize powder, areca fiber and urea formaldehyde resin are mixed thoroughly. A composite plate is designated as UF100 for plate prepared with various proportions of areca fiber, maize powder and $100 \mathrm{ml}$ of UF and similarly for other plates. Thoroughly mixed Areca fibers and resin were 
pressed in a hydraulic hot press at a temperature of $140^{\circ} \mathrm{C}$ and a pressure of $2 \mathrm{MPa}$ for 30 minutes.

\section{Biodegradable Test}

Biodegradation of a substance is the process in which microorganisms use the substance as food source. It occurs by reaction between the enzymes secreted by the organism and the polymer chains or additives, which make up the compound. The degradation involves bond scission reactions in the backbone of polymers, so that the original form disappears. Appropriate conditions in terms of temperature, pressure and nutrients concentrations have to be maintained for optimization of rate of biodegradation. Usually, biodegradation products are not toxic or environmentally harmful. According to IS standard, the specimen of $50 \mathrm{~mm}$ wide and 75 $\mathrm{mm}$ long were kept in compost for a period of 2-3 month with $\mathrm{pH}$ maintained and observing the changes in the weight of the specimen. In this experiment, the specimen is kept in compost for a period of 60 days. It has been observed that at the initial stages the specimens shows increase in the weights for nearly one month and then starts loosing its weight showing the biodegradability. It is a very slow process since the areca fibers don't decompose at faster rate.

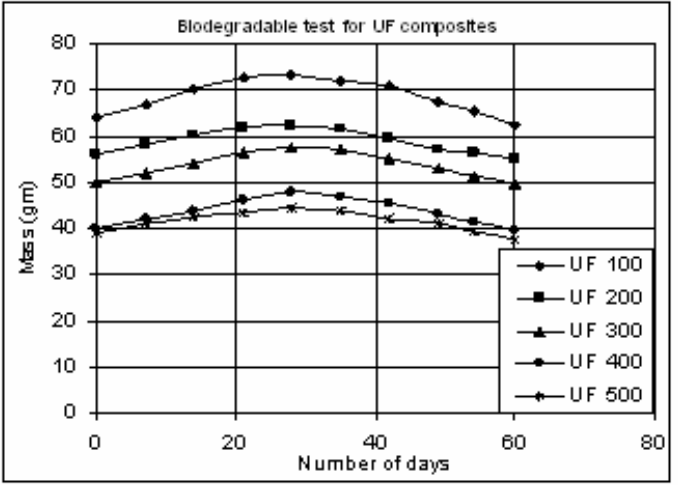

Fig. 3- Biodegradable Test Result for UF composites Fig. 3 shows that the UF composites absorb some amount of moisture present in the compost in the early stages and there is an increase in their weight for some period of time. After this, there is decrease in the weight because of reaction between the enzymes secreted by the organism and the polymer chains or additives, which make up the compound. This process continues and gradually looses its weight with the time.

\section{Swelling Test}

Most natural fibers absorbed more water compared to synthetic fibers. Water is predominantly absorbed at the fiber interface and matrix. The effect of this absorbed water is to degrade the properties such as tensile strength. The specimens were prepared from a $12 \mathrm{~mm}$ thickness plate with size $50 \mathrm{~mm}$ wide and $75 \mathrm{~mm}$ long. The specimens were immersed in water for a period of 7-15 days. The moisture content in the composite is measured by the weight gain of the material in regular intervals. The percent moisture content is expressed as the ratio of increase in weight to the weight of dry specimen.

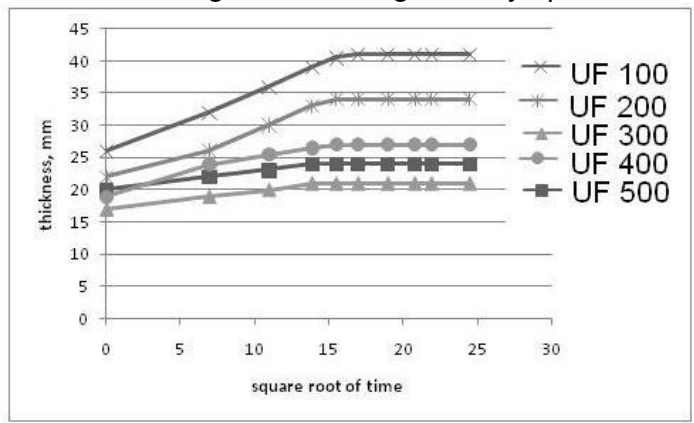

Fig. 4- Swelling test result for UF composites Fig. 4 shows the thickness Vs square root of time curves for areca fiber and maize powder reinforced UF composite plates. The thickness increases with decrease in areca fiber and increase in maize powder upto $600 \mathrm{gms}$ of Areca and $400 \mathrm{gms}$ of maize powder. Maximum thickness is $42 \mathrm{~mm}$ for UF 100 composite plate compared to remaining composite plates and remains stable. The specifications were immersed in water for a period of 30 days. The moisture content in the composite is measured by the gain of the material in regular intervals. Figure shows the amount in the composite increase with time and later it become constant. It absorbs about $30-40 \%$ of its thickness. Compared to conventional wood-based particle board it is very small where water absorption for wood-based particle board is more than $40 \%$. Therefore this experiment shows that the composite made of areca fibers and maize powder have significantly less water absorption. The swelling is good with optimum weight fraction of fibres and maize powder in composite which was $4: 1$ ratio. Further variation in the weight ratio increase swelling properties.

\section{Abbreviation}

ASTM - American Society for Testing and Materials

\section{Conclusion}

Areca fiber and maize powder reinforced UF composite are biodegradable and looses its weight. The process is very slow. The areca composite exhibits an excellent resistance to moisture compared to wood based particleboard, which have more than $40 \%$.The swelling property of the composites with weight fraction ratio $4: 1$ of areca fibres to maize powder was proved good than others. The composite exhibits good moisture resistance. $300 \mathrm{ml}$ Composite plate gives better results compared to others. The 
natural composites proved to be promising materials for packaging and other engineering and domestic applications.

\section{References}

[1] Swamy R.P., Mohan Kumar G.C., Vrushabhendrappa Y. and Vince Joseph (2001) Proceedings of 2nd international conference on ICTACEM 2001, Indian Institute of Technology, Kharagpur.

[2] Bharath K.N., Swamy R.P. (2009) IJRTE, Academy Publisher, 1 (5), 60-62.

[3] Verma I.K., Kamaesvari A. (1986) Journal of Polymer Science, 3, 23-30.

[4] Prasad S.V., Pavithran C, Rohatgi P.H. (1983) Journal of Material Science, 18, 1443-1450.

[5] Ghosh P., Ganguly P.K. (1993) Plastic rubber and composite production, 20, 171-177.

[6] Sridhar M.K., Basavarajappa G., Kasturi S.G. (1982) Ind.J.Text.Res.7, 87.

[7] Giridhar J., Kishore R.M., Rao V.G.K. (1986) Journal of reinforced plastics and composites, 5, 141-150. 